\title{
Delayed diagnosis of 22q11 deletion syndrome due to late onset hypocalcemia in a 11-year-old girl with imperforated anus
}

\author{
Dong-Yoon Yoo, MD', \\ Hae Jung Kim, MD', \\ Kee Hyun Cho, MD', \\ Eun Byul Kwon, MD', \\ Eun-Gyong Yoo, MD, PhD'
}

${ }^{1}$ Department of Pediatrics, CHA Bundang Medical Center, CHA University, Seongnam, ${ }^{2}$ Department of Pediatrics, Andong General Hospital, Andong, Korea
Received: 11 October, 2016 Revised: 10 November, 2016 Accepted: 20 December, 2016

Address for correspondence:

Eun-Gyong Yoo, MD, PhD

Department of Pediatrics, CHA Bundang Medical Center, CHA University, 59 Yatap-ro, Bundang-gu, Seongnam 13496, Korea

Tel: +82-31-780-1999

Fax: +82-31-780-5239

E-mail:pedyoo@cha.ac.kr

https://orcid.org/0000-0002-6452$655 X$
Neonatal hypocalcemia and congenital heart defects has been known as the first clinical manifestation of the chromosome 22q11.2 deletion syndrome (22q11DS). However, because of its wide clinical spectrum, diagnosis of 22q11DS can be delayed in children without classic symptoms. We report the case of a girl with the history of imperforate anus but without neonatal hypocalcemia or major cardiac anomaly, who was diagnosed for 22q11DS at the age of 11 after the onset of overt hypocalcemia. She was born uneventfully from phenotypically normal Korean parents. Imperforate anus and partial cleft palate were found at birth, which were surgically repaired thereafter. There was no history of neonatal hypocalcemia, and karyotyping by GTG banding was normal. At the age of 11, hypocalcemia (serum calcium, $5.0 \mathrm{mg} / \mathrm{dL}$ ) and decreased parathyroid hormone level (10.8 $\mathrm{pg} / \mathrm{mL}$ ) was noted when she visited our Emergency Department for fever and vomiting. The 22q11DS was suspected because of her mild mental retardation and velopharyngeal insufficiency, and a microdeletion on chromosome $22 q 11.2$ was confirmed by fluorescence in situ hybridization. The 22q11DS should be considered in the differential diagnosis of hypocalcemia at any age because of its wide clinical spectrum.

Keywords: 22q11 Deletion syndrome, Hypocalcemia, DiGeorge Syndrome, Hypoparathyroidism, Imperforate anus

\section{Introduction}

The chromosome 22q11.2 deletion syndrome (22q11DS) is the most common microdeletion syndrome with an estimated incidence of 1 in 4,000 live births ${ }^{1)}$. Heterozygous deletion in chromosome $22 \mathrm{q} 11.2$ is found in most patients, and about $10 \%$ of patients have microdeletion that was inherited from affected parents ${ }^{1)}$. The main clinical features of 22q11DS include congenital heart defect, hypocalcemia due to hypoparathyroidism, thymic hypoplasia, palatal cleft and mental retardation ${ }^{1,2)}$. Hypoparathyroidism is most likely detected from symptoms of hypocalcemia, such as seizure, tremors or tetany that usually manifests during the neonatal period, and neonatal hypocalcemia is usually considered as one of the first manifestation of 22q11DS ${ }^{2}$. The hypocalcemia can be transient, although it may recur later in life. Late onset hypocalcemia in adolescence or adulthood have been reported in patients with $22 q 11 D S$ due to its highly variable phenotype $e^{2,3)}$.

The extreme diversity of clinical presentations makes 22q11DS without well-known phenotype a diagnostic challenge. Because of possible underdiagnoses, true prevalence of this syndrome can be much higher than reported ${ }^{4,5}$. We hereby report the case of a girl with the history of imperforate anus, partial cleft palate, and mild mental retardation, but without history of neonatal hypocalcemia or major cardiac anomaly, who was diagnosed for 22q11DS 
at the age of 11 after the onset of overt hypocalcemia.

\section{Case report}

An 11-year-old girl visited our Emergency Department with fever, cough, abdominal pain and vomiting. Hypocalcemia (serum calcium, $5.0 \mathrm{mg} / \mathrm{dL}$; ionized calcium, $0.74 \mathrm{mM}$ ) was noted on laboratory analysis, with normal albumin $(4.3 \mathrm{mg} / \mathrm{dL})$, and upper normal limit level of phosphorus $(5.6 \mathrm{mg} / \mathrm{dL})$.

She was born with $3,040 \mathrm{~g}$ of body weight at 37 weeks of pregnancy at our hospital and was the second child of phenotypically normal Korean parents. Imperforate anus with rectovestibular fistula and partial cleft palate were found at birth. Atrial septal defect (ASD, 3.5-mm width) was diagnosed on echocardiography performed on the first day of life. However, the karyotyping revealed normal chromosomal pattern by GTG banding. Descending colostomy was performed on the first day of life and followed by colostomy repair at 9 months of age. Pena operation (posterior sagittal anorectoplasty) was performed at 4 months of age and transposition anoplasty was done at 7 months of age. Palatoplasty for cleft palate was performed at 14 months of age, and again at 9 years of age, velopharyngeal insufficiency was surgically corrected by superiorly based pharyngeal flap with lateral port control. Echocardiography at 20 months of age showed no intracardiac anomaly, suggesting spontaneous closure of previously observed ASD. She had suffered from frequent respiratory tract infections with otitis media and chronic constipation, but there was no history of severe systemic infection. Her developmental milestones were delayed, and she was diagnosed for mild intellectual disability at 8 years of age (Intelligence quotient 57 on Korean Wechsler intelligence scale for children). She was attending a public school without specific behavioral problems, although her academic performance was poor.

On the third day of life, her calcium $(9.2 \mathrm{mg} / \mathrm{dL})$, phosphorus $(4.5 \mathrm{mg} / \mathrm{dL})$, and ionized calcium $(1.05 \mathrm{mM} / \mathrm{L})$ levels were normal. Her calcium level was also normal on preoperative screening before surgery at 4,7 , and 9 months of age $(10.5,10.8$, and $10.6 \mathrm{mg} / \mathrm{dL}$, respectively). Her calcium level was in low normal range on laboratory studies at 20 months and 7 years of age (9.1 and $8.9 \mathrm{mg} / \mathrm{dL}$, respectively). The parents denied any history of hypocalcemic symptoms during her infancy or childhood.

Her facial features appeared mildly dysmorphic, with hypertelorism, short philtrum and small down-turned mouth. Hypernasal speech was not observed. At the time of hypocalcemia onset at 11 years of age, her height was $141 \mathrm{~cm}$ (25th percentile) with weight $31 \mathrm{~kg}$ (10th-25th percentile). Her midparental height was $157 \mathrm{~cm}$ (10th-25th percentile). Her wrist X-ray showed bone age of 12 years without any evidence of rickets. Serum magnesium level was normal $(1.63 \mathrm{mg} / \mathrm{dL})$. The parathyroid hormone (PTH) level was inappropriately low $(10.8 \mathrm{pg} / \mathrm{mL}$; reference rage, $15-65 \mathrm{pg} / \mathrm{mL})$ considering her plasma calcium level, suggesting hypocalcemia due to hypoparathyroidism. Serum $25(\mathrm{OH})$ D level was also decreased
(11.4 ng/mL; reference range, $30-100 \mathrm{mg} / \mathrm{mL}$ ). Her thyroid function was normal (thyroid-stimulating hormone, $0.28 \mathrm{uIU} /$ $\mathrm{mL}$; free $\mathrm{T} 4,1.68 \mathrm{pg} / \mathrm{mL}$ ).

Intravenous calcium (calcium gluconate, $100 \mathrm{mg} / \mathrm{kg}$ ) was given during the first 3 days after admission, followed by oral calcium (calcium lactate, $300 \mathrm{mg} / \mathrm{kg} /$ day). Vitamin D (calcitriol, $0.75 \mu \mathrm{g} /$ day) treatment was started on the 2 nd hospital day. She was discharged on the 6th hospital day when her calcium level was $6.5 \mathrm{mg} / \mathrm{dL}$. Her calcium level increased to $8.3 \mathrm{mg} / \mathrm{dL}$ on follow-up visit at 1 week after discharge, and her PTH level was still low $(9.0 \mathrm{pg} / \mathrm{mL})$. Although $25(\mathrm{OH}) \mathrm{D}$ level has been normalized ( 25.5 and $30.5 \mathrm{ng} / \mathrm{mL}$ after 2 months and 3 months, respectively) after treatment, daily administration of calcium (calcium carbonate, $62.5 \mathrm{mg} / \mathrm{kg} /$ day) and calcitriol $(0.5 \mu \mathrm{g} /$ day) was required to maintain normocalcemia (serum calcium 9.2 and $8.3 \mathrm{mg} / \mathrm{dL}$ after 2 and 3 months, respectively).

22q11DS was suspected based on her history of velopharyngeal insufficiency and mental retardation, and fluorescence in situ hybridization analysis confirmed a deletion of chromosome 22q11.2 (Fig. 1).

\section{Discussion}

The present case suggests that the diagnosis of 22q11DS can be delayed in those without major clinical features. Our patient did not have neonatal hypocalcemia or major cardiac anomaly, although she had imperforate anus, velopharyngeal insufficiency, and delayed development, and subtle but characteristic facial features of $22 \mathrm{q} 11 \mathrm{DS} \mathrm{S}^{5}$.

The chromosome $22 \mathrm{q} 11$ region is very unstable, and misalignment of chromosome-specific low-copy repeats (LCR22A-H) during nonallelic homologous recombination can lead to the deletion of the 22q11.2 region ${ }^{6}$. Approximately $90 \%$

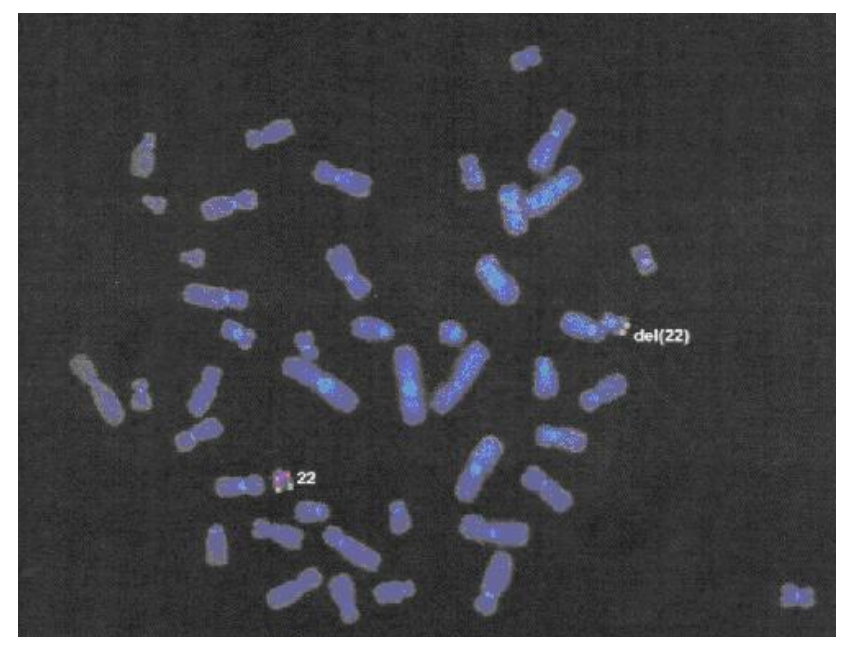

Fig. 1. Fluorescence in situ hybridization analysis using DiGeorge region probe, Vysis LSI N25 (spectrum orange, $126 \mathrm{~kb}$ ) and control chromosome probe that detects 22 q13 outside the critical DiGeorge syndrome region, Vysis LSI ARSA (spectrum green, $334 \mathrm{~kb}$ ), revealed a deletion of chromosome 22q11.2 by binding of 22q11.2 probe to only one chromosome in our patient. 
of patients with 22q11DS have the $3 \mathrm{Mb}$ (LCR22A-D) deletion, while less than $10 \%$ have shorter $(\sim 1.5 \mathrm{Mb})$ deletion such as LCR22A-B deletion ${ }^{6}$. The haploinsufficiency of genes located at 22q11.2, especially $T B X 1$, can disturb the early morphogenesis of many organs including parathyroid gland, thymus and facial structures $^{6}$. The 22q11DS encompasses very wide clinical spectrum, including DiGeorge syndrome, velocardiofacial syndrome, and conotruncal anomaly face syndrome ${ }^{5}$.

Neonatal hypocalcemia due to hypoparathyroidism has traditionally been known as the first manifestation that has been reported in $43 \%-60 \%$ of patients with $22 \mathrm{q} 11 \mathrm{DS}^{2,7)}$. However, in our case, the patient had obviously normal calcium levels throughout her infancy, and overt hypocalcemia was first noticed at 11 years of age. Low normal range of calcium levels during her early childhood could be a sign of subclinical hypoparathyroidism, but PTH level was not checked before the onset of overt hypocalcemia.

A recent study including 138 adults with 22q11DS reported $80 \%$ of patients have a lifetime history of hypocalcaemia ${ }^{8}$. The spectrum of parathyroid gland function in 22q11DS ranges from severe neonatal hypocalcemia to latent hypoparathyroidism ${ }^{2,8}$. The PTH secretory reserve is inadequate compared with normal population in patients with latent hypoparathyroidism ${ }^{3}$, and it becomes insufficient that can lead to evident hypocalcemia when calcium requirement increases such as during adolescence, pregnancy, surgery, infection, or any physiologic stresses ${ }^{2,9)}$.

Hypocalcemia is one of the unique features of proximal deletions (LCR22A-D or LCR22A-B) in patients with $22 \mathrm{q} 11 \mathrm{DS}^{6}$. However, it manifests with a wide clinical spectrum even in the same family ranging from hypocalcemic hypoparathyroidism to normocalcemia with latent hypoparathyroidism, although the latent hypoparathyroidism can evolve to frank hypocalcemic hypoparathyroidism in adulthood ${ }^{10)}$. A transition from subclinical to overt hypoparathyroidism in a child with 22q11DS has also been reported ${ }^{11)}$.

A provocation test using sodium bicarbonate infusion was reported to be able to evaluate residual parathyroid function in normocalcemic patients with $22 \mathrm{q} 11 \mathrm{DS}^{8)}$. Hypocalcemia may also be worsened by carbonated beverages such as colas ${ }^{9)}$. Regular lifelong follow-up of calcium, magnesium, and PTH levels are required in patients with $22 \mathrm{q}_{11} \mathrm{DS}^{12}$. Calcium and vitamin D supplements are recommended to patients with 22q11DS, regardless of whether they had been diagnosed with hypocalcaemia, however, iatrogenic hypercalcemia, which can result in renal calculi and renal failure, should be avoided".

Vitamin D deficiency is very common in Korean children, but calcium and PTH levels were normal in most children with vitamin D deficiency ${ }^{13)}$. Our patient also had vitamin D deficiency at the time of hypocalcemia onset. It is possible that vitamin D deficiency may have contributed to the development of hypocalcemia in the patient with latent hypoparathyroidism. However, calcium supplement was persistently required after vitamin D replenishment in our patient, suggesting that vitamin D deficiency was not the main cause of hypocalcemia.

Congenital heart defects are one of main clinical feature of

Table 1. Incidences of major and minor clinical features in $22 q 11$ deletion syndrome

\begin{tabular}{|c|c|c|c|c|c|c|c|}
\hline Variable & Botto et al. ${ }^{14)}$ & Cancrini et al. ${ }^{4}$ & Lee et al. $^{15)}$ & Fomin et al. ${ }^{5)}$ & Hiéronimus et al. ${ }^{2)}$ & Friedman et al. ${ }^{16)}$ & Bassett et al. $^{17)}$ \\
\hline Published year & 2003 & 2014 & 2004 & 2010 & 2006 & 2016 & 2015 \\
\hline Country & USA & Italia & Korea & Brazil & France & Israel & Canada \\
\hline Sex, male:female & $43(21: 22)$ & $228(112: 116)$ & $43(19: 24)$ & $14(8: 6)$ & $19(11: 8)$ & $8(3: 5)$ & $78(36: 42)$ \\
\hline Age (yr), mean $\pm S D$ (range) & Infancy & Mean $2(0-36)$ & $5.3 \pm 4.2(2-23)$ & Mean 8 (0-18) & Median 18 (0-48) & $>10(10-57)$ & $31.5 \pm 10.5$ \\
\hline Hypocalcemia & $21 \%$ & N/A & $47 \%$ & $36 \%$ & $38 \%$ & $38 \%$ & $64 \%$ \\
\hline Neonatal hypocalcemia & N/A & $43 \%$ & N/A & N/A & $19 \%$ & N/A & $14 \%$ \\
\hline Hypoparathyroidism & N/A & $19 \%$ & $16 \%$ & $29 \%$ & $50 \%$ & $25 \%$ & N/A \\
\hline Cardiac anormalies & $81 \%$ & $79 \%$ & $84 \%$ & $86 \%$ & $58 \%$ & $50 \%$ & $25.8 \%$ \\
\hline Gastrointestinal anomalies & $3 \%$ & $6 \%$ & $2.3 \%$ & - & - & - & N/A \\
\hline Renal anomalies & $2.3 \%$ & N/A & - & - & - & - & $6 \%$ \\
\hline Velopharyngeal insufficiency & $14 \%$ & $31 \%$ & $\mathrm{~N} / \mathrm{A}$ & $\mathrm{N} / \mathrm{A}$ & $26 \%$ & $13 \%$ & $42 \%^{a)}$ \\
\hline Cleft palate & $12 \%$ & $10 \%$ & $19 \%$ & N/A & $16 \%$ & $13 \%$ & $31 \%^{b)}$ \\
\hline Intellectual disability & N/A & $70 \%$ & $\mathrm{~N} / \mathrm{A}$ & N/A & $84 \%$ & N/A & $92.3 \%$ \\
\hline Developmental delay & N/A & $48 \%$ & N/A & N/A & N/A & $75 \%$ & N/A \\
\hline Behavior abnormalities & N/A & $7 \%$ & N/A & N/A & $50 \%$ & $50 \%$ & N/A \\
\hline Psychiatric disorders & $\mathrm{N} / \mathrm{A}$ & $5 \%$ & $\mathrm{~N} / \mathrm{A}$ & $\mathrm{N} / \mathrm{A}$ & $10 \%$ & $13 \%$ & $58 \%^{c)}$ \\
\hline (Recurrent) Infections & N/A & $56 \%$ & N/A & $50 \%$ & $32 \%$ & $25 \%$ & $39 \%{ }^{d)}$ \\
\hline Thymic aplasia & $28 \%$ & $28 \%$ & $16 \%$ & N/A & $10 \%$ & N/A & N/A \\
\hline Thyroid disease & - & $2 \%$ & $7.6 \%$ & $7.1 \%$ & - & - & $26 \%$ \\
\hline Dysmorphic face & $80 \%$ & $100 \%$ & N/A & $79 \%$ & $100 \%$ & $88 \%$ & $100 \%$ \\
\hline
\end{tabular}

SD, standard deviation; N/A, not available.

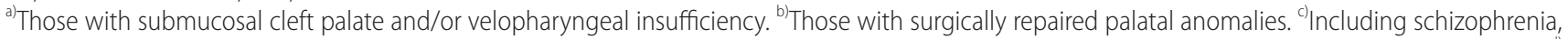
major depression, anxiety disorder, impulse control disorder, and substance use disorder (23\% if schizophrenia ascertainment subgroup only). d) Recurrent pneumonia. 
22q11DS. Although serious cardiac anomalies were present in most patients in earlier studies, the prevalence seems to be about $40 \%$ according to recent papers ${ }^{9}$. Conotruncal defects, especially tetralogy of Fallot are the main forms ${ }^{5}$. Our patient had a small ASD, which was closed spontaneously. The prevalence of ASD was reported as $12 \%$ in patients with $22 \mathrm{q} 11 \mathrm{DS}^{4)}$.

Table 1 summarizes the incidences of major and minor clinical features of 22q11DS in recent publications ${ }^{2,45,14-17)}$. The prevalence of each clinical feature is different according to the age of patients and data sources. It seems that the prevalence of hypocalcemia and psychiatric disorders increase with age, whereas the prevalence of cardiac anomalies seems to be higher in the younger age groups. Intellectual disability and dysmorphic face were observed in most patients.

A delay in the diagnosis of 22q11DS with noncardiac symptoms has been reported in a recent study including 228 patients with $22 \mathrm{q} 11 \mathrm{DS} \mathrm{S}^{4)}$. Among them, $71 \%$ of patients were diagnosed before 2 years of age, mainly related to the presence of cardiac anomalies and neonatal hypocalcemia. In patients diagnosed after 2 years of age, developmental delay, minor cardiac defects, recurrent infections and facial features led to the diagnosis of $22 \mathrm{q}_{11 \mathrm{DS}}{ }^{4}$. According to a recent study, $31 \%$ of patients with 22q11DS were diagnosed after age 10 years ${ }^{16)}$. The basis for clinical suspicion was diverse, but once brought to attention, additional symptoms such as characteristic facial features and developmental delay were easily noted in most patients ${ }^{16)}$. Although our patient presented some of the characteristic facial features such as hypertelorism, short philtrum, and small down-turned mouth, it was subtle and did not lead to suspicion of 22q11DS before the onset of overt hypocalcemia.

The incidence of anorectal malformation is approximately 1 in 5,000 live births ${ }^{18)}$. More than half of anorectal malformation is associated with other congenital anomalies such as urogenital and cardiovascular anomalies. A number of congenital syndromes, such as Down syndrome, are accompanied with anorectal malformations, however, the 22q11DS is not considered as the major etiologic condition of anorectal malformations ${ }^{18}$. However, anorectal malformation, including imperforate anus and symptomatic anal stenosis, was reported

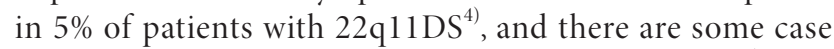
reports on symptomatic anal anomalies in $22 \mathrm{q}_{11 \mathrm{DS}^{19}}$. Our patient had undergone multiple major surgeries for the correction of imperforate anus, but 22q11DS was not suspected at that time.

There are several reports on the delayed diagnosis of 22q11DS, and recent cases of 22q11DS diagnosed after 10 years of age are summarized in Table $2^{3,20-27)}$. Most of them $(8$ of 12) visited the hospital because of hypocalcemic seizure. However, only 16.7\% (2 of 12) had documented history of

Table 2. Summary of case reports of $22 q 11$ deletion syndrome diagnosed after 10 years of age

\begin{tabular}{|c|c|c|c|c|c|c|c|c|c|}
\hline Study & Age & Sex & $\begin{array}{l}\text { Cause of } \\
\text { diagnosis }\end{array}$ & $\begin{array}{l}\text { Ca level } \\
\text { (mg/dL) }\end{array}$ & $\begin{array}{c}\text { Neonatal } \\
\text { hypocalcemia }\end{array}$ & $\begin{array}{l}\text { Dysmorphic } \\
\text { face }\end{array}$ & $\begin{array}{c}\text { Cardiac } \\
\text { abnormality }\end{array}$ & $\begin{array}{l}\text { Neuropsychiatric } \\
\text { problems }\end{array}$ & $\begin{array}{l}\text { Other associated } \\
\text { abnormality }\end{array}$ \\
\hline Maalouf et al." & 32 & M & Hypocalcemia, seizure & 7.0 & Unknown & + & None & Learning difficulty & - \\
\hline Johnston et al. ${ }^{20)}$ & 29 & $\mathrm{~F}$ & $\begin{array}{l}\text { Symptomatic } \\
\text { hypocalcemia }\end{array}$ & 6.56 & Transient & + & None & Learning difficulty & $\begin{array}{l}\text { Velopharyngeal } \\
\text { insufficiency }\end{array}$ \\
\hline \multirow[t]{2}{*}{ Özkale et al. ${ }^{21)}$} & 13 & M & Hypocalcemic seizure & 5.8 & Permanent & + & none & Autism, MR & - \\
\hline & 12 & $\mathrm{~F}$ & Seizure & normal & Unknown & + & ASD & Mild MR & $\begin{array}{l}\text { Recurrent } \\
\text { respiratory } \\
\text { infection }\end{array}$ \\
\hline \multirow[t]{2}{*}{ Hyun et al. ${ }^{22)}$} & 12 & M & hypocalcemic seizure & 6.5 & Unknown & + & Rt aortic arch & $\begin{array}{l}\text { Learning difficulty } \\
\text { mild MR }\end{array}$ & $\begin{array}{c}\text { Cleft palate, } \\
\text { decreased T cell } \\
\text { number }\end{array}$ \\
\hline & 12 & M & Hypocalcemic seizure & 6.9 & Unknown & + & PDA & Learning difficulty & - \\
\hline Nakada et al. ${ }^{23)}$ & 36 & $\mathrm{~F}$ & $\begin{array}{l}\text { Clouding of } \\
\text { consciousness }\end{array}$ & 8.3 & Unknown & + & TOF & Learning difficulty & $\begin{array}{c}\text { Decreased CD } 8 \\
\text { T cell, Hashimoto' } \\
\text { thyroiditis }\end{array}$ \\
\hline Kambo et al. ${ }^{24)}$ & 17 & M & Hypocalcemic seizure & 6.64 & Unknown & + & $\begin{array}{l}\text { Mild cardiac } \\
\text { abnomality }\end{array}$ & MR & $\begin{array}{l}\text { Cleft palate, } \\
\text { parathyroid } \\
\text { hypoplasia }\end{array}$ \\
\hline Korpaisarn et al. ${ }^{25)}$ & 26 & M & $\begin{array}{l}\text { Carpopedal spasm, } \\
\text { numbness, tingling }\end{array}$ & 6.0 & Unknown & + & None & Mild MR & - \\
\hline Eryilmaz et al. ${ }^{26)}$ & 11 & M & Hypocalcemic seizure & 6.3 & Unknown & + & None & Delayed milestone & $\begin{array}{l}\text { Recurrent } \\
\text { respiratory } \\
\text { infection }\end{array}$ \\
\hline An et al. ${ }^{27)}$ & 13 & M & Hypocalcemic seizure & 6.7 & Unknown & + & None & Learning difficulty & Cleft palate \\
\hline Present case & 11 & $\mathrm{~F}$ & Hypocalcemia & 5.0 & None & + & ASD & Learning difficulty & $\begin{array}{c}\text { Imperforate } \\
\text { anus, cleft palate, } \\
\text { velopharyngeal } \\
\text { insufficiency }\end{array}$ \\
\hline
\end{tabular}

MR, mental retardation; ASD, atrial septal defect; PDA, patent ductus arteriosus, TOF, Tetralogy of Fallot. 
neonatal hypocalcemic events and 50\% (6 of 12) had no cardiac abnormalities, suggesting that the diagnosis may be delayed if the patient has neither hypocalcemic symptoms nor cardiac anomalies. Dysmorphic facial features were usually recognized after the diagnosis of 22q11DS, and learning disability and/or mental retardation was present in most patients. In our case, diagnosis was delayed until the onset of overt hypocalcemia, probably due to the absence of major cardiac anomaly and neonatal hypocalcemia.

A correct diagnosis is important in patients with 22q11DS because of the increased risk for later-onset medical and neuropsychiatric problems, including schizophrenia ( $>20$-fold increase), anxiety disorder, epilepsy, and Parkinson disorder ${ }^{9)}$. Many treatable conditions may be anticipated and features may accumulate over time ${ }^{177}$. The risk of premature mortality, especially sudden and unexpected death, also increases ${ }^{28)}$.

Our case suggest that imperforate anus, without major cardiac anomaly, can be a clinical presentation of 22q11DS, and that 22q11DS should be considered in the differential diagnosis of hypocalcemia in any age because of its wide clinical spectrum. Furthermore, patients with 22q11DS should be informed of the symptoms of hypocalcemia that may develop later, and periodic screening for serum calcium level should be considered.

\section{Conflict of interest}

No potential conflict of interest relevant to this article was reported.

\section{References}

1. Bassett AS, McDonald-McGinn DM, Devriendt K, Digilio MC, Goldenberg P, Habel A, et al. Practical guidelines for managing patients with 22q11.2 deletion syndrome. J Pediatr 2011;159:332-9.e1.

2. Hiéronimus S, Bec-Roche M, Pedeutour F, Lambert JC, Wagner-Malher K, Mas JC, et al. The spectrum of parathyroid gland dysfunction associated with the microdeletion 22q11. Eur J Endocrinol 2006;155:47-52.

3. Maalouf NM, Sakhaee K, Odvina CV. A case of chromosome 22q11 deletion syndrome diagnosed in a 32-year-old man with hypoparathyroidism. J Clin Endocrinol Metab 2004;89:4817-20.

4. Cancrini C, Puliafito P, Digilio MC, Soresina A, Martino S, Rondelli $\mathrm{R}$, et al. Clinical features and follow-up in patients with 22q11.2 deletion syndrome. J Pediatr 2014;164:1475$80 . \mathrm{e} 2$.

5. Fomin AB, Pastorino AC, Kim CA, Pereira CA, CarneiroSampaio M, Abe-Jacob CM. DiGeorge syndrome: a not so rare disease. Clinics (Sao Paulo) 2010;65:865-9.

6. Burnside RD. 22q11.21 Deletion syndromes: a review of proximal, central, and distal deletions and their associated features. Cytogenet Genome Res 2015;146:89-99.

7. Taylor SC, Morris G, Wilson D, Davies SJ, Gregory JW.
Hypoparathyroidism and 22q11 deletion syndrome. Arch Dis Child 2003;88:520-2.

8. Nagasaki K, Iwasaki Y, Ogawa Y, Kikuchi T, Uchiyama M. Evaluation of parathyroid gland function using sodium bicarbonate infusion test for 22q11.2 deletion syndrome. Horm Res Paediatr 2011;75:14-8.

9. Fung WL, Butcher NJ, Costain G, Andrade DM, Boot E, Chow EW, et al. Practical guidelines for managing adults with 22q11.2 deletion syndrome. Genet Med 2015;17:599609.

10. Cuneo BF, Driscoll DA, Gidding SS, Langman CB. Evolution of latent hypoparathyroidism in familial 22q11 deletion syndrome. Am J Med Genet 1997;69:50-5.

11. Hasegawa T, Hasegawa Y, Aso T, Koto S, Tanaka N, Asamura $S$, et al. The transition from latent to overt hypoparathyroidism in a child with CATCH 22 who showed subnormal parathyroid hormone response to ethylenediaminetetraacetic acid infusion. Eur J Pediatr 1996;155:255.

12. Cheung EN, George SR, Costain GA, Andrade DM, Chow EW, Silversides CK, et al. Prevalence of hypocalcaemia and its associated features in 22q11.2 deletion syndrome. Clin Endocrinol (Oxf) 2014;81:190-6.

13. Chung IH, Kim HJ, Chung S, Yoo EG. Vitamin D deficiency in Korean children: prevalence, risk factors, and the relationship with parathyroid hormone levels. Ann Pediatr Endocrinol Metab 2014;19:86-90.

14. Botto LD, May K, Fernhoff PM, Correa A, Coleman K, Rasmussen SA, et al. A population-based study of the 22q11.2 deletion: phenotype, incidence, and contribution to major birth defects in the population. Pediatrics 2003;112(1 Pt 1):101-7.

15. Lee JS, Choi JH, Yoo HW. The endocrine manifestations and growth of the patients with 22q11.2 microdeletion syndrome. J Korean Soc Pediatr Endocrinol 2004;9:66-71.

16. Friedman N, Rienstein S, Yeshayahu Y, Gothelf D, Somech R. Post-childhood presentation and diagnosis of DiGeorge syndrome. Clin Pediatr (Phila) 2016;55:368-73.

17. Bassett AS, Chow EW, Husted J, Weksberg R, Caluseriu O, Webb GD, et al. Clinical features of 78 adults with 22q11 deletion syndrome. Am J Med Genet A 2005;138:307-13.

18. Wang C, Li L, Cheng W. Anorectal malformation: the etiological factors. Pediatr Surg Int 2015;31:795-804.

19. Al-Mudaffer M, Puri P, Reardon W. Symptomatic anal anomalies in chromosome 22q11 deletion syndrome: a report of three patients. Pediatr Surg Int 2006;22:384-6.

20. Johnston PC, Donnelly DE, Morrison PJ, Hunter SJ. DiGeorge syndrome presenting as late onset hypocalcaemia in adulthood. Ulster Med J 2008;77:201-2.

21. Özkale M, Erol İ. 22q11.2 microdeletion in two adolescent patients who presented with convulsion. Turk Pediatri Ars 2014;49:70-3.

22. Hyun JW, Chung HK, Kim SH, Choi YJ, Kim SJ, Kim HS, et al. Two cases of chromosome 22q11.2 deletion syndrome diagnosed in 12-year-old boys with hypocalcemic seizures. 
J Epilepsy Res 2012;2:43-7.

23. Nakada Y, Terui K, Kageyama K, Tsushima Y, Murakami H, Soma Y, et al. An adult case of 22q11.2 deletion syndrome diagnosed in a 36-year-old woman with hypocalcemia caused by hypoparathyroidism and Hashimoto's thyroiditis. Intern Med 2013;52:1365-8.

24. Kambo JS, Girgis CM, Champion BL, Wall JR. Delayedonset hypoparathyroidism in an adolescent with chromosome 22Q11 deletion syndrome. Endocr Pract 2011;17:e123-5.

25. Korpaisarn S, Trachoo O, Sriphrapradang C. Chromosome 22q11.2 deletion syndrome presenting as adult onset hypoparathyroidism: clues to diagnosis from dysmorphic facial features. Case Rep Endocrinol 2013;2013:802793.

26. Eryılmaz SK, Baş F, Satan A, Darendeliler F, Bundak R, Günöz H, et al. A patient with 22q11.2 deletion syndrome: case report. J Clin Res Pediatr Endocrinol 2009;1:151-4.

27. An YW, Jung MJ, Yu JS, Lee YS, Yoo HW. A case of CATCH22 syndrome with first attack of hypocalcemic seizure at 13 years of age. Korean J Pediatr 2004;47:794-8.

28. Bassett AS, Chow EW, Husted J, Hodgkinson KA, Oechslin E, Harris L, et al. Premature death in adults with 22q11.2 deletion syndrome. J Med Genet 2009;46:324-30. 